\title{
A Computational Study on the Reduction Behavior of Iron Ore/Carbon Composite Pellets in Both Single and Multi-layer Bed Rotary Hearth Furnace
}

\author{
SOUMYADEEP DASGUPTA, SOORAJ SALEEM, PRAKASH SRIRANGAM, \\ MICHAEL AUINGER, and GOUR G. ROY
}

\begin{abstract}
A phenomenological model for the reduction of iron ore/carbon composite pellets in a multi-layer bed rotary hearth furnace has been developed. A single pellet model has been scaled up to a multi-pellet layer version in a computationally efficient way. The multi-layer pellet bed has been conceived as single column of identical pellets in a rectangular enclosure, assuming symmetry of the pellet bed in horizontal direction. The column walls are considered opaque with respect to heat transfer but allow heat radiation to reach the pellet surface through multiple reflections from the wall. The time-temperature-transformation and time-temperature-chemical heat absorption contours are presented to provide a better understanding of the reduction process. Finally, the net heat flux and carbon monoxide generation, emerging from the multi-layer bed system has been generated, which may be used as source and sink terms for CFD simulations in the free board of the RHF.
\end{abstract}

https://doi.org/10.1007/s11663-020-01778-z

(C) The Author(s) 2020

\section{INTRODUCTION}

DEPLETION of high grade ore, the demand for utilizing low grade iron ore and coal fines, iron bearing steel plant solid waste, and environmental concerns ${ }^{[1]}$ have lead researchers to look for alternative routes of iron making. One such route involves RHF (rotary hearth furnace), where iron ore and coal fines in the form of cold bonded composite pellets/ briquettes are converted to direct reduced iron (DRI) nuggets for subsequent melting in the electric arc furnace. RHF is a donut shaped furnace where a rotating hearth carries the pellets/briquettes through various temperature regimes to produce DRI. Some of the successful commercial processes based of RHF are Inmetco, FASTMELT and ITmk3. ${ }^{[2,3]}$ The major advantages of RHF lie in the flexibility of the input material. Iron bearing steel plant solid waste, low grade iron ore fines cold bonded with

SOUMYADEEP DASGUPTA, SOORAJ SALEEM, and GOUR G. ROY are with the Department of Metallurgical and Materials Engineering, Indian Institute of Technology Kharagpur, Kharagpur, West Bengal, 721302, India. PRAKASH SRIRANGAM and MICHAEL AUINGER are with the Warwick Manufacturing Group, University of Warwick, Coventry CV4 7AL, UK. Contact e-mail: m.auinger@warwick.ac.uk

Manuscript submitted July 17, 2019

Article published online February 3, 2020. low grade carbonaceous material in the form of pellets and briquettes, could be utilized and thereby they are more eco-friendly reducing the solid waste disposal.

Extensive research work has been carried out to understand the reduction of iron ore coal composite pellets, which are mostly limited to experimental investigations for single pellets. The amount of carbon inside the pellet as well as the effects of pellet size, shape, additives, heating rates, and compactness of the pellets have been studied in detail. ${ }^{[4-8]}$ However, very few studies have been reported on multi-layer bed pellet reduction. Sohn and Fruehan ${ }^{[9]}$ investigated the role of coal volatiles on the kinetics of the composite pellet reduction in an infra-red heated laboratory scale multi-layer RHF. For a single pellet, the volatiles come out fast and thereby do not contribute much to its reduction. However, for a multi-layer system, volatiles coming out from the bottom layers participate in the reduction of upper layers pellets during their ascent. Huang et al. ${ }^{[10]}$ studied the reduction of iron ore-coal composite pellets in a tall bed hearth furnace and reported higher metallization at the top of the bed compared to the bottom layer, in the presence of coal with a low content of volatiles. A higher degree of metallization at the bottom of the bed compared to the topmost zone was found in the case of coal with higher volatile content. It is apparent that there have been very few investigations on the multi-layer bed RHF, and particularly no attempts have been made to simulate the RHF using mathematical models on the continuum 
level. Although few semi-empirical models ${ }^{[6,11-14]}$ have been reported to estimate rate parameters and to predict the phase evolution during the course of reduction; no mathematical model has so far been developed for RHF. The present study thereby seeks to develop a comprehensive model beginning from the single pellet domain and scaling it up to multiple pellet layer bed to analyze and predict the degree of reduction that different layers will experience. This study takes into account the three dimensional heat, mass and momentum equations using the COMSOL ${ }^{\circledR}$ multiphysics software. Studying a particular symmetry element representative of the multi-layer pellet bed allows us to effectively study the whole furnace with process being computationally efficient. The uniquely framed multi-pellet layer system at a lower computational cost clarifies several important factors responsible for pellet reduction in the furnace.

\section{MODEL DESIGN AND GOVERNING EQUATIONS}

The model is separated into a single pellet reduction model (Section II-A) followed by a multi-layer pellet model (Section II-B), derived from the single pellet model in order to emulate similar conditions as in a rotary hearth furnace. For simplicity, the chemical reactions in both models have been implemented by the step-wise reduction of iron oxides by gaseous intermediates like $\mathrm{CO}$ and $\mathrm{CO}_{2}$. The chemical reactions involved are stated as follows,

$$
\begin{gathered}
3 \mathrm{Fe}_{2} \mathrm{O}_{3}+\mathrm{CO}=2 \mathrm{Fe}_{3} \mathrm{O}_{4}+\mathrm{CO}_{2} \\
1.202 \mathrm{Fe}_{3} \mathrm{O}_{4}+\mathrm{CO}=3.807 \mathrm{Fe}_{0.947} \mathrm{O}+\mathrm{CO}_{2} \\
\mathrm{Fe}_{0.947} \mathrm{O}+\mathrm{CO}=0.947 \mathrm{Fe}+\mathrm{CO}_{2} \\
\mathrm{CO}_{2}+\mathrm{C}=2 \mathrm{CO}
\end{gathered}
$$

The last reaction is the carbon gasification reaction (i.e., Boudouard reaction), which is widely considered as the rate controlling reaction. ${ }^{[8]}$ Since this reaction is highly endothermic, it affects the reduction of the pellets by creating a non-isothermal process. ${ }^{[14]}$

\section{A. Single Pellet}

A spherical single composite pellet is taken for the basis of this model as shown in Figure 1. This model assumes the pellet to be composed of pure haematite and carbon in specific molar ratios.

\section{Heat transfer}

The heat transfer in the pellet is governed by Eq. [1]. $T$ is the temperature of the pellet and $\rho$ is the solid density of the pellet, which is a function of temperature and composition of the pellet and thus changes as a function

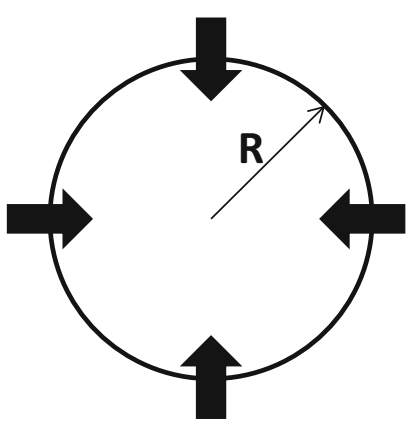

Fig. 1-Simplified geometry of a single iron ore carbon composite pellet, used during the simulations. The arrows indicate the direction of heat flow by radiation at the boundaries.

of time, depending on species evolution within the pellet. The solid species are considered here for the calculation of density. $C_{\mathrm{p}}$ is the heat capacity at constant pressure, changing in a similar manner as $\rho$ with the evolution of chemical constituents of the reaction. In other words, both $\rho$ and $C_{\mathrm{p}}$ are arithmetic means of the individual constituents in the pellets at a particular time. In Eq. [2], $k_{\text {eff }}$ is the effective thermal conductivity of the pellet, which is defined by Akiyama et al. ${ }^{[15]}$

$$
\begin{gathered}
\rho C_{\mathrm{P}} \frac{\partial T}{\partial t}+\nabla\left(-k_{\mathrm{eff}} \nabla T\right)=\dot{Q} \\
k_{\mathrm{eff}}=\frac{2}{3}\left(\frac{\phi}{k_{g}}+\frac{1-\phi}{k_{s}}\right)^{-1}+\frac{1}{3}\left(\phi k_{g}+(1-\phi) k_{s}\right)^{-1}
\end{gathered}
$$

Here $k_{\mathrm{s}}$ is the average solid conductivity which is calculated on basis of the expression suggested by Coetsee et al. ${ }^{[5]}$ that is the logarithmic mean value of the constituents composing the pellet. $\phi$ is the porosity of the pellet. The parameter $k_{\mathrm{g}}$ represents the thermal conductivity of the emitted gases present in the interstices of the solid pellet. $\dot{Q}$ is the heat source that represents the total heat effects of reactions involved and is defined as,

$$
\dot{Q}=\sum_{i} R_{i}\left(-\Delta H_{i}\right)
$$

$R_{i}$ and $\Delta H_{i}$ represent the reaction rate $\left(\mathrm{mol} \mathrm{m}^{-3} \mathrm{~s}^{-1}\right)$ and the heat of the $i$ th reaction $\left(\mathrm{J} \mathrm{mol}^{-1}\right)$, respectively. The values of parameters $C_{\mathrm{p}}$ and $\Delta H_{i}$ as a function of temperature were obtained from the works Donskoi and McElwain ${ }^{[11,12]}$

The initial temperature $T_{0}$ of the pellet is uniform. A radiation boundary condition is chosen for heat transfer at the boundary owing to the fact that the major mode of heat transfer in rotary hearth furnace is usually found out to be primarily governed by radiation. Thus the approximation is made that the single pellet is exposed to an environment with $T_{\mathrm{f}}$ (furnace temperature) as the ambient temperature. The direction shown by the arrows in Figure 1 indicate the direction that heat flow always occurs from the surface of the pellets towards their interior, since $T_{\mathrm{f}}$ is higher than $T$. Thus, the boundary conditions at the pellet surface $(r=R)$ are defined as follows, 


$$
k_{\mathrm{eff}} \nabla T=\varepsilon \sigma\left(T_{\mathrm{f}}^{4}-T^{4}\right)
$$

In all simulations, the value for $\varepsilon$ was assumed to be 1 . $\sigma$ represents the Stefan-Boltzmann constant. $T_{\mathrm{f}}$ is the temperature of the furnace, $T$ being the pellet temperature.

\section{Mass transfer}

Mass transfer equations are important for the gaseous components generated in-situ during the reaction. The gases generated due to the reaction are mainly $\mathrm{CO}_{2}$ and $\mathrm{CO}$ and are assumed to move through the micropores within the solid pellets by mode of diffusion. ${ }^{[16]}$ Modeling of gas evolution from within the pellet and gas flow through a porous media with transient geometry during the entire reduction process is computationally very intensive. Hence, in the present study, the concept of effective diffusivity is invoked and reliable values have been taken from literature. ${ }^{[16]}$ The transient mass transfer equation for the gaseous component is written as follows,

$$
\frac{\partial c_{k}}{\partial t}+\nabla \cdot\left(-D_{k} \nabla c_{k}\right)=S_{k}
$$

The concentration of the $k$ th gaseous component $\left(c_{k}\right)$ and the diffusion coefficient of the species $\left(D_{k}\right)$ were defined accordingly. $S_{k}$ is the source term for the $k$ th gaseous species, which contributes to the generation/consumption.

The initial concentration of gases within the pellets are kept at $c_{k, 0}$ which equals zero for both $\mathrm{CO}$ and $\mathrm{CO}_{2}$ to prevent errors during numerical computation of the differential equation.

The boundary conditions at the pellet surface $(r=R)$ are set as follows:

$$
D_{k} \nabla T(r=R)=-k_{m}\left(c_{k}-c_{k, \infty}\right)
$$

Here, $k_{\mathrm{m}}$ is the mass transfer coefficient in the concentration boundary layer. This is calculated by the classical Ranz Marshall correlation. ${ }^{[17]}$

$$
\mathrm{Sh}=2.0+0.6 \mathrm{Re}^{0.5} \mathrm{Sc}^{0.33}
$$

Sh is the Sherwood number, Re is the Reynold's number, and Sc is the Schmidt number.

\section{B. Multi-pellet Bed}

The pellet dimensions are similar to the case of a single pellet except the rectangular enclosure surrounding the stack of multiple pellet layers now being rectangular. This rectangular enclosure represents a single columnar section of the pellet layers (see Figure 2), inserted in a rotary hearth furnace. Assuming symmetry of the pellet bed in horizontal direction, only a single column of pellets needs to be considered to represent the whole pellet bed. The column walls are considered opaque with respect to heat transfer (no flux condition) to the adjacent columns. But the walls allow heat radiation to reach the pellet surface through multiple reflections from the wall. Any other heat exchange between columns is manipulated by adjusting

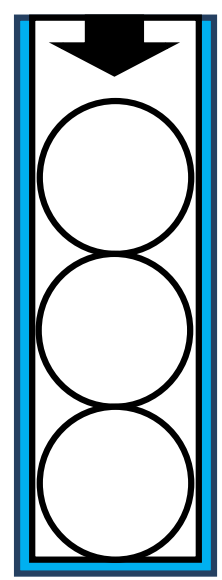

Fig. 2-Schematic geometry of the multiple layer pellet bed, used for the simulations. The arrow indicates the direction of heat flow from the top boundary by radiation inside the enclosure, which gets reflected at the blue highlighted boundaries (acting as radiation reflecting mirrors).

the radiation view factor. The upper boundary of the rectangular enclosure, shown in Figure 2, is kept at a certain distance from the topmost pellet. This distance has impact on the view factors for the radiative heat flux. This parameter has been tuned for experimental validation for the best representation of the involved process. It should be noted that the top boundary of the rectangular enclosure is kept at a constant furnace temperature $T_{\mathrm{f}}$ and serves as the heat source for pellet bed heating.

\section{Heat transfer}

The governing heat transfer phenomena are described in detail in Section (II-A-1). The entire system is initially kept at a temperature of $800 \mathrm{~K}$, except for the top boundary, which is set equal to the furnace temperature $T_{\mathrm{f}}$. Hence, the topmost boundary acts as the radiative heat source for the entire system. The heat thus transmitted by the combined mode of radiation and conduction from the top surface is transferred throughout the container and in turn heats the pellets layer by layer. The emissivities $(\varepsilon)$ of all surfaces in the present study are assumed to be 1 . The equations for the pellet surfaces may be written as follows,

$$
k_{\mathrm{eff}} \nabla T(r=R)=\sum_{j}^{n} \varepsilon \sigma F_{i, j}\left(T_{i}^{4}-T_{j}^{4}\right)
$$

Here $F_{i, j}$ refers to the view factor seen by the $j$ th surface on the $i$ th surface. $n$ Denotes the total number of surfaces, contributing to heat transfer by radiation in the system.

The side and the bottom walls act as perfectly reflecting mirrors, heat escaping through them is thus zero. This assumption is made based on the fact that the net heat input to the system of pellets presented in our investigation will be contributed by the top boundary of the rectangular enclosure. To keep that assumption intact we assume no heat escaping through the side and bottom walls. This heat is used for the heating of pellets. No heat flux boundary condition is used at the wall. 


\section{Laminar flow for compressible fluids}

The equations solved are as follows,

$$
\rho_{g}\left(\frac{\partial u}{\partial t}+(u \cdot \nabla) u\right)=\nabla \cdot\left[-\rho_{g} I+\mu\left(\nabla u+(\nabla u)^{T}\right)-\frac{2}{3} \mu(\nabla \cdot u) I\right]-\rho_{g} g j
$$

$$
\frac{\partial \rho_{g}}{\partial t}+\nabla \cdot\left(\rho_{g} u\right)=0
$$

These equations are solved for the domain within the rectangular enclosure constituting the zone which surrounds the pellets. Equation [9] constitutes the momentum conservation and Eq. [10] is the mass conservation equation. $\rho_{g}$ is assumed to be the density of air as a function of temperature and $I$ is the identity tensor. The last term in Eq. [9] represents the volume force, which simulates natural convection by incorporating the effect of gravitational force. $\mu$ is the kinematic viscosity of air, which is $1.48 \times 10^{-5} \mathrm{~m}^{2} / \mathrm{s}$. Although this effect may be small in the current statement nevertheless this gives an idea of the flow within the pellet bed.

No convection has been used for the initial conditions $(t=0)$ and the side and bottom walls of the domain as well as the pellet walls were set to no-slip conditions $(u$ $=0)$.

At the top wall of the rectangular domain, an outlet condition is defined as

$$
\left[-\rho I+\mu\left(\nabla u+(\nabla u)^{T}\right)-\frac{2}{3} \mu(\nabla . u) I\right] \vec{n}=0
$$

\section{Mass transfer}

The generalized mass transfer equation for the entire system enclosed by the rectangular domain is,

$$
\frac{\partial c_{k}}{\partial t}+\nabla \cdot\left(-D_{k} \nabla c_{k}\right)+u \cdot \nabla c_{k}=S_{k}
$$

Here, again the concentration of the $k$ th gaseous component is taken as $c_{k}$ together with the diffusion coefficient of the species $D_{k}$, respectively. $S_{k}$ is the source term for the $k$ th gaseous species, which contributes to the consumption/generation of the gaseous species as a consequence of the reactions taking place within the pellet. It needs to be noted that $S_{k}$ has the value zero for areas outside the pellet, where no reaction takes place. Outside the pellet $D_{k}$ is set to zero, meaning that the transport of gases occurs only by the means of convection. The term $u$ is calculated by simulating a natural convection outside the pellet domain, solving the Navier Stokes' equation for compressible flow. The initial concentrations of $\mathrm{CO}$ and $\mathrm{CO}_{2}$ have been set to a very small positive value of $0.001 \mathrm{~mol} / \mathrm{m}^{3}$. At the side and bottom walls of the domain, no flux conditions were assumed.

\section{Chemical Kinetics}

The chemical kinetics is a chief governing factor to account for the iron produced at the end of the process from a self-reducing pellet. Assuming the carbon and the iron oxide particles are small, the reaction rates are assumed to be independent of particle size and first order with respect to the reactants involved. The rate law for the Boudouard reaction therefore may be written as ${ }^{[18]}$

$$
R_{C}=k_{C} m_{C}\left(P_{\mathrm{CO}_{2}}-P_{\mathrm{CO}_{2}}^{\text {equilib }}\right)
$$

$k_{c}$ is the carbon gasification rate constant and it follows the Arrhenius law. The rate equation for the iron oxide reductions are represented in a similar form,

$$
R_{\mathrm{FexOy}}=k_{\mathrm{FexOy}} m_{\mathrm{FexOy}}\left(P_{\mathrm{CO}}-P_{\mathrm{CO}}^{\text {equilib }}\right)
$$

Here $x=1,2$ and 3 for $y=1,3,4 . k_{C}$ and $k_{\mathrm{FexOy}}$ are the rate coefficients for the carbon gasification reaction and iron oxide reduction, which are both assumed to obey the Arrhenius law.

The rate parameters are an important tuning parameter which is different depending on raw materials. They are modified in to obtain the best agreement with experimental results for this particular simulation setup.

\section{RESULTS AND DISCUSSION}

\section{A. Comparison Between Experimental and Computational Results in a Single Pellet}

The degree of reduction (DOR) of the iron oxide pellet is represented by the equation,

$$
\text { DOR }=\frac{\text { Weight of removed oxygen from the iron oxide }}{\text { Total weight of reducible oxygen in the iron oxide }}
$$

This parameter is of primary importance and has been well-documented experimentally and hence used to validate our model. Using experimental results obtained by De Carvalho et al. ${ }^{[8]}$ a reasonable correlation between simulated and experimental data has been obtained, as shown in Figure 3. It is to be mentioned that the rate parameters represented by Eqs. [13] through [15] have been adjusted around the literature

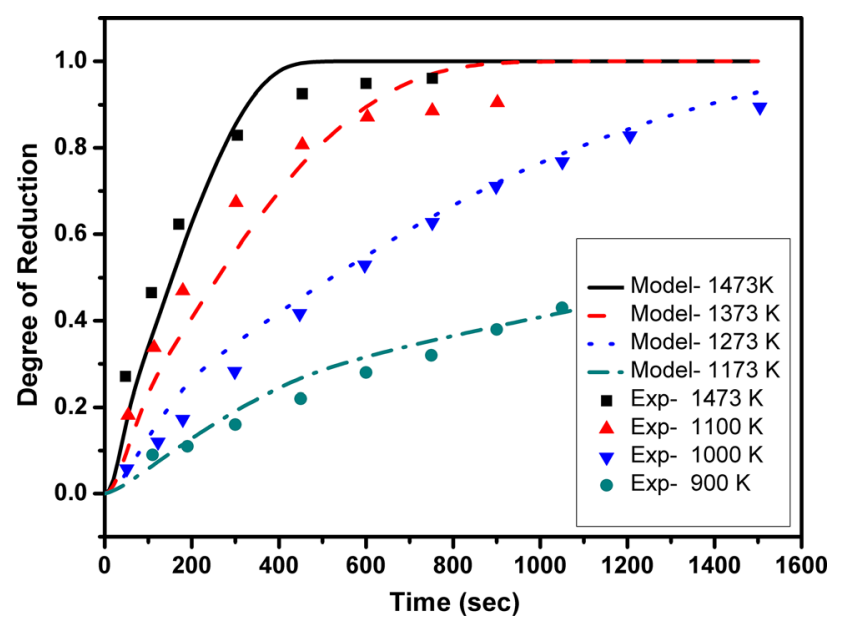

Fig. 3-Comparison between experimental and simulated results for different furnace temperatures for a single pellet for $\mathrm{C} / \mathrm{O}$ ratio of 1.5 for a pellet of $15 \mathrm{~mm}$ diameter. 
data to match experimental results. Therefore, the optimized rate parameters (see Table I) represent the apparent rate parameters that consider the effect of additional influences of heat and mass transfer via these intrinsic parameters.

It should be kept in mind that the model assumes pure carbon mixed with hematite and does not consider the impurities associated with the carbon. The degrees of reduction in the experiments by De Carvalho et al. ${ }^{[8]}$ were reported along with gas analysis during the experiments. The slightly increased degree of reduction in the simulations may thus be attributed to the fact that the impurities within the pellets from the experiments ${ }^{[8]}$ hamper the reduction rate which would otherwise lead to an increased degree of reduction in a idealistic process.

\section{B. Chemical Species Evolution and Heat Evolution During Reduction in a Single Pellet}

Figure 4 exhibits the evolution of the chemical species with time. It is to be noted that in spite of being produced in-situ during the reaction, magnetite gets quickly reduced to wustite hence leading to the shape of the curve for magnetite. The evolution of $\mathrm{CO}$ stops when Boudouard reaction stops. The evolution of the $\mathrm{CO}_{2}$ stops when all the reduction reaction stops and the $\mathrm{CO}_{2}$ is utilized for Boudouard reaction. This is also illustrated in the same Figure.

Table I. Estimated Frequency Factors and Activation Energies of the Involved Reactions

\begin{tabular}{lcc}
\hline Reactions & $\begin{array}{c}\text { Frequency } \\
\text { Factor }\end{array}$ & $\begin{array}{c}\text { Activation Energy } \\
(\mathrm{kJ} / \mathrm{mol})\end{array}$ \\
\hline Haematite to magnetite & $2.6 \times 10^{4}$ & -150 \\
Magnetite to wustite & $1 \times 10^{5}$ & -100 \\
Wustite to iron & $2.4 \times 10^{5}$ & -175 \\
Boudouard reaction & $4 \times 10^{6}$ & -215 \\
\hline
\end{tabular}

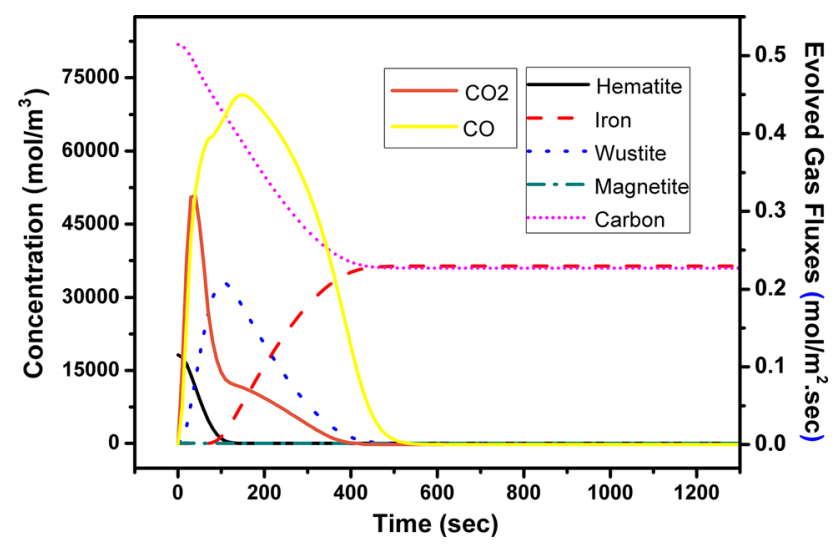

Fig. 4-The concentration of the species involved in reaction with time. The study shown here is for a single $15 \mathrm{~mm}$ diameter pellet with a furnace temperature of $1473 \mathrm{~K}\left(1200{ }^{\circ} \mathrm{C}\right)$. The $\mathrm{C} / \mathrm{O}$ ratio is 1.5 .

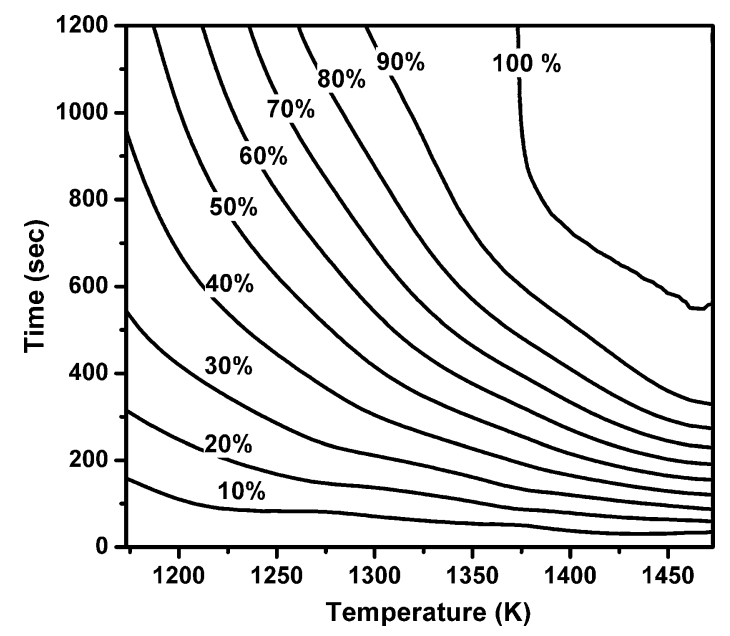

Fig. 5-Contour plot for iron formation as a function of temperature and time in a single $15 \mathrm{~mm}$ pellet. The pellet constitutes a mixture of hematite and carbon in a weight ratio of 1.5 . The contour lines indicate the percentage of iron being produced.

For a comprehensive outlook for iron formation as a function of time and furnace temperature, a two-dimensional contour plot is shown in Figure 5. This plot gives us an estimate regarding the necessary temperature at which the furnace has to operate in order to achieve the required pellet reduction rate.

Figure 6 offers an outlook on the impact of furnace temperature with time on the heat absorption within the pellet due to the reactions. The highest amount of heat is absorbed initially when the endothermic Boudouard reaction is predominant. The amount of heat absorption decreases as the reduction proceeds and the exothermic reaction becomes dominant, leading to reduction of the iron oxides.

\section{Effect of Initial Pellet Composition in a Single Pellet}

The effect of the initial iron and carbon composition in the pellets is shown in Figure 7. Haematite is mixed with carbon at different $\mathrm{C} / \mathrm{O}$ ratios of $1.0,1.2$, and 1.5. The impact of the starting composition can be seen by the degree of reduction which is slightly altered during the process.

The trends observed in Figure 7 indicate that with an increase of the $\mathrm{C} / \mathrm{O}$ ratio in the pellet, a higher degree of reduction is achieved at shorter time, indicating a faster rate of reduction. At higher reduction times, reducing the carbon amount in the pellet may be advisable owing to similar DOR, despite of increasing $\mathrm{C} / \mathrm{O}$ ratio in the pellet. This may lead to significant reduction of cost of production in the industrial scale.

\section{Experimental Validation of Multi-layer Pellet Bed Model}

Multi-layer pellet bed experiments are essential to predict the degree of reduction of the pellet layers. However, it is difficult to check the temporal degree of reduction for each layer individually. Halder and Fruehan $^{[19]}$ made a custom RHF simulator and derived 


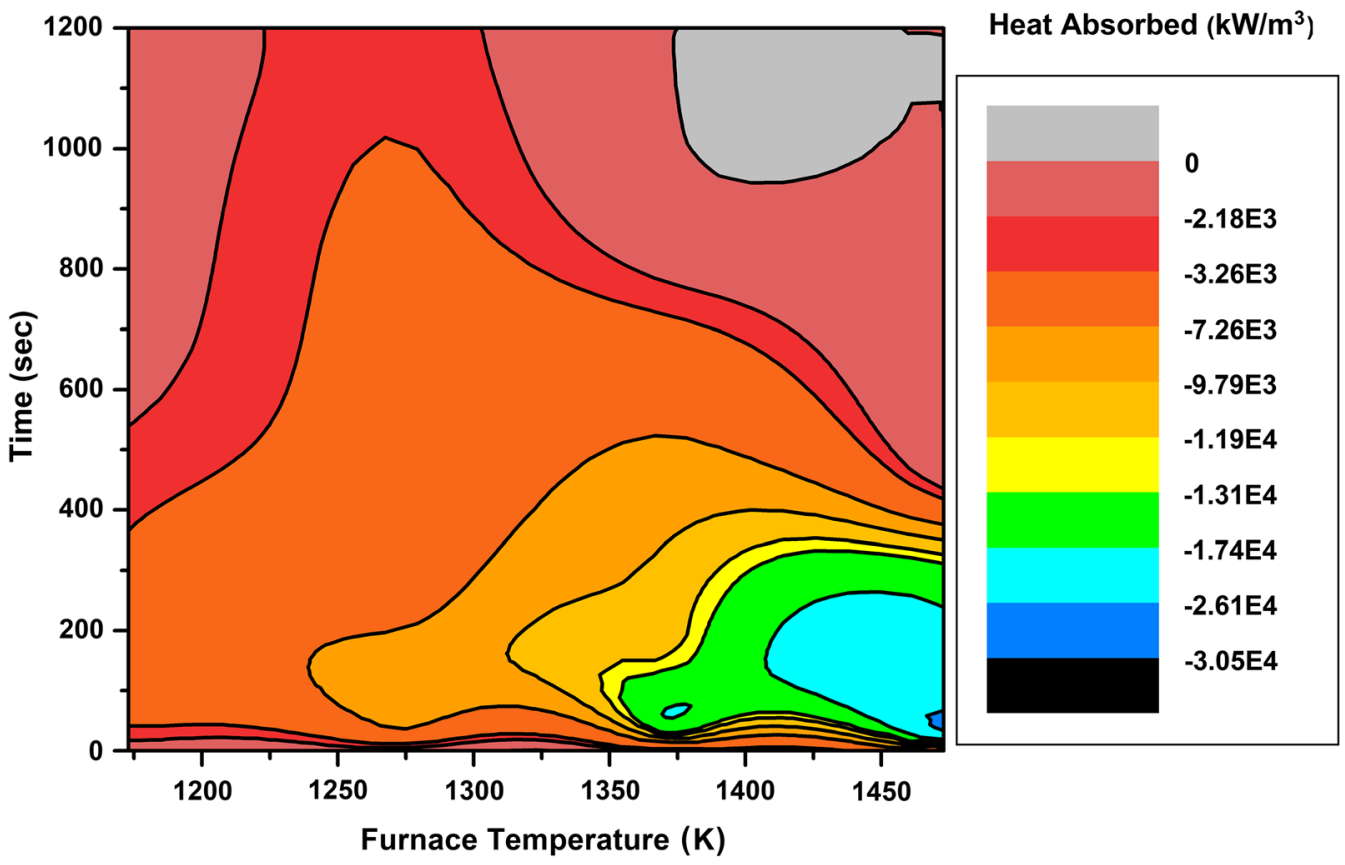

Fig. 6 - Contour plot for chemical heat absorbed as a function of temperature and time in a single $15 \mathrm{~mm}$ pellet. The pellet constitutes a mixture of hematite and carbon with a $\mathrm{C} / \mathrm{O}$ ratio of 1.5 .

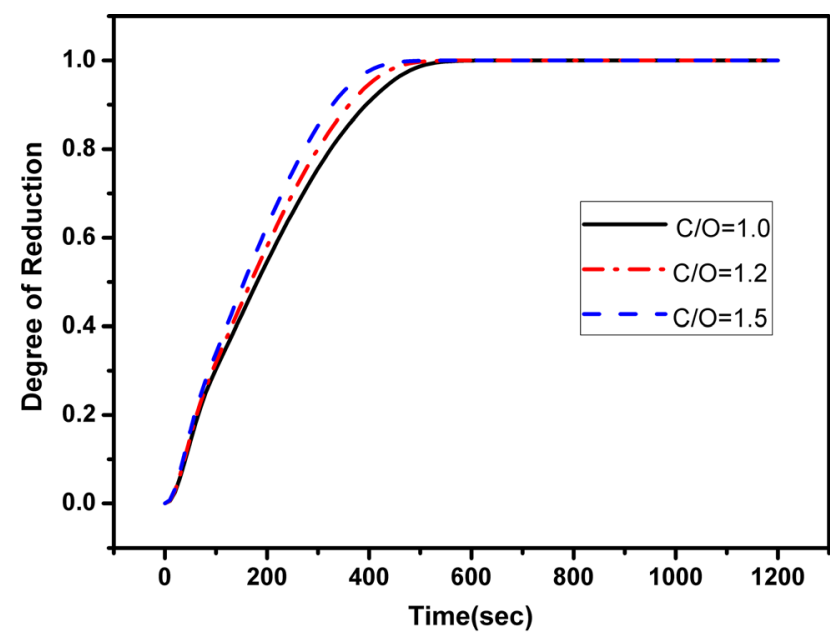

Fig. 7-Degree of reduction with time for different $\mathrm{C} / \mathrm{O}$ mixture in the ore.

the degree of reduction as a function of time via off-gas analyses. The calculated DOR follows the DOR of Hematite-coal-char composite pellets ${ }^{[19]}$ shown in Figure 8 for the top and the middle pellet in a three-pellet layer bed. The calculations have been performed, keeping the kinetic parameters same as in Table I. These kinetic parameters are solely derived from tuning the parameters in the single pellet case and are kept same for multi-layer pellet bed system. Similar DOR indicate that the apparent kinetic rate parameters of the

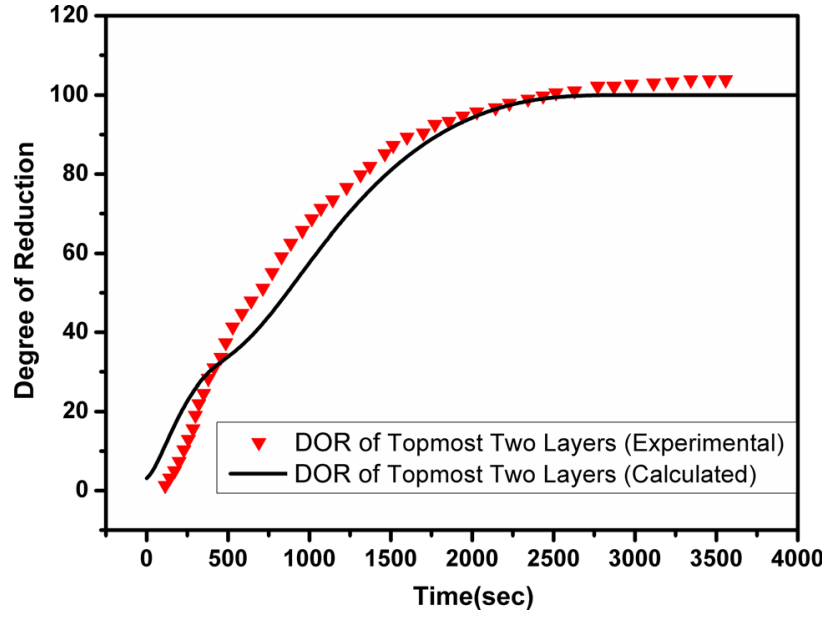

Fig. 8 - Calculated and experimental degree of reduction of the topmost two layers in a three-pellet layer bed.

Hematite-coal-char pellets presumably resemble the apparent kinetic parameters utilized in the present multi-pellet bed simulations. The slight mismatch between the modeled data and the experimental data may be attributed to extensive sintering occurring in pellet layers, which is not accounted for in our current model. To keep the modeled setup similar to the experimental setup, the distance between the top boundary of the multi-layer pellet bed enclosure has been kept at $6 \mathrm{~mm}$ which is the height of the heat source 


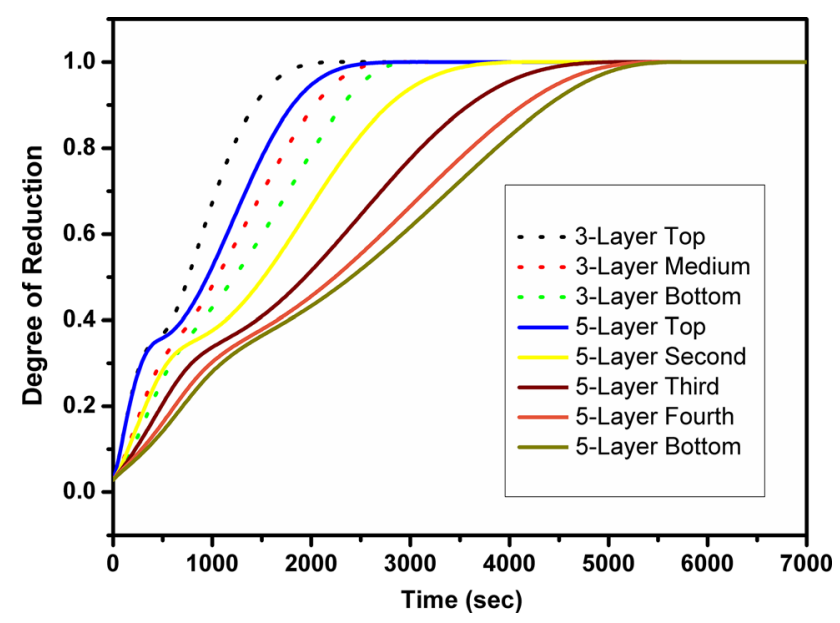

Fig. 9-Degree of reduction with time for multi-layer pellet beds at $1523 \mathrm{~K}\left(1250{ }^{\circ} \mathrm{C}\right)$ with a $\mathrm{C} / \mathrm{O}$ ratio of 1 for each pellet.

(infra-red lamps) used in the RHF simulator by Halder and Fruehan. ${ }^{[9]}$ This height has been maintained for all multi-layer bed simulations to ensure an accurate depiction of the process. The $\mathrm{C} / \mathrm{O}$ ratio, pellet diameter, and furnace temperature have also been kept same as in the experimental study.

As the reduction proceeds, the utilization of $\mathrm{CO}$ for the reduction process decreases and thus we see the increase in partial pressure of $\mathrm{CO}$. The initial $\mathrm{CO}_{2}$ signal is high due to the reactions and gradually reduces to become almost zero. Although the reduction reactions stop, the Boudouard reaction keeps on going due to the high temperatures and the excess $\mathrm{CO}$ present in the pellet. This reaction utilizes $\mathrm{CO}_{2}$ resulting in its decrease. Thus, once the $\mathrm{CO}_{2}$ content becomes zero, the reduction process has stopped.

\section{E. Degree of Reduction in Multi-layer Pellet Bed}

The productivity of RHF is limited by the number of layers over the hearth due to heat transfer limitations towards the lower layers. Mathematical models help to further understanding of heat transfer in a multi-layer bed and thereby allow decisions on the suitable number of layers in the RHF.

Figure 9 provides valuable insights on the time required for the reduction of pellet layers in the RHF. Three- and five-layer pellet beds at $1523 \mathrm{~K}\left(1250{ }^{\circ} \mathrm{C}\right)$ were investigated. We see a significant difference between the top and the bottom layers in both cases. It is necessary to emphasize that an increase in the number of layers leads to significantly lower DOR even though the relative position of the pellet in the furnace remains unchanged. This is in agreement with the temperature profile and computed reaction rates since the amount of heat absorbed per pellet per unit time is reduced as the number of pellet layers increases. The view factor also plays a significant role and thus the majority of the heat is received by the top layer leading to a gradual decrease of reduction in the layers towards the bottom.

\section{F. Variation of Different Properties in Five-Pellet Bed Layer}

Two-dimensional contours for temperature and off-gas velocity in a five-layer pellet bed have been shown in Figure 10(a) through (f) after 100 seconds, 4000 seconds, and 8000 seconds. The temperature down the pellet bed decreases as expected. This leads to poor DOR in the lower pellet layers. The air is denser in the low temperature regime and becomes lighter as temperature increases towards the top. Therefore, the pressure is higher at the bottom than at the top. With time, the pressure difference decreases since the off-gas evolution stops and temperature becomes uniform across the whole bed. The velocity variation thus can be explained from the pressure point of view. During the escape from the enclosure, the velocity increases and creates a vortex near the escape zone and that is why we observe the increase in magnitude at the top of the bed (Figures 10(d) and (e)). Again, as the off-gas generation decreases, the velocity decreases with time. With the completion of the reduction, the vortex disappears and the gas flow stops.

\section{G. Temperature Evolution and Heat Absorbed in Multi-pellet Bed System}

The evolution of the average pellet temperature in three-layer and five-layer pellet beds is shown in Figure 11. The three-pellet bed reaches the furnace temperature much faster than the five-layer bed. A dip in the temperature evolution slope indicates the impact of the endothermic chemical reactions during the process.

The heat flux input for the pellet bed is shown in Figure 12 along with the evolving $\mathrm{CO}$ flux from these systems. Once the absorbed heat reaches zero, it indicates the end of the reduction process. This happens much earlier for the three-layer bed than for the five-layer bed. The peak amount of heat absorbed, however, remains almost identical and the time when it absorbs the majority of heat is similar for both pellet beds. This indicates that the process is initially dominated by the topmost hematite pellets which absorb the heat equally, irrespective of the pellet bed it belongs to. After a while, the temperature of the bed increases and the amount of heat entering decreases.

The evolved carbon monoxide has a higher peak value for the three-layer bed. The pellet layers heat up faster for the three-layer bed leading to higher evolution in the initial stages contrary to the five-layer bed system. The average temperature increase in the five-layer bed is slower leading to lower CO generation initially. However, the total amount of formed $\mathrm{CO}$ is much higher for 


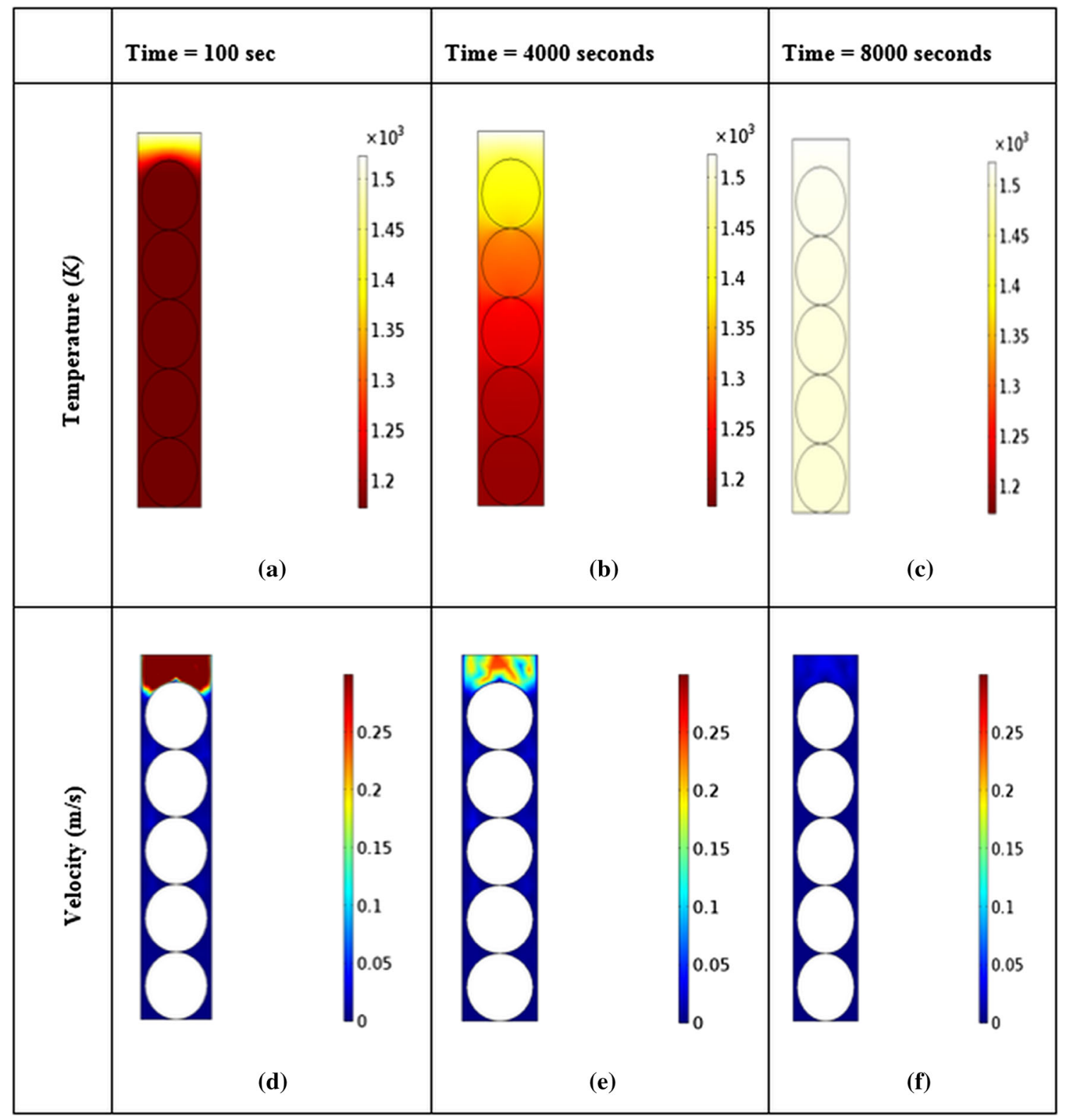

Fig. 10 - Temperature (top row) and off-gas velocity (bottom row) variation across the multi-layer pellet bed with pellets having $\mathrm{C} / \mathrm{O}$ ratio of 1 at $100 \mathrm{~s}(a, d), 4000 \mathrm{~s}(b, e)$, and $8000 \mathrm{~s}(c, f)$.

the five-layer bed as can be seen from comparing the areas under the $\mathrm{CO}$ flux curves. $\mathrm{CO}$ evolution stops once heat absorption becomes zero, since the reduction stops.

\section{CONCLUSIONS}

The developed model serves as first approach to simulate the conditions in a simplified rotary hearth furnace process. This study provides us with valuable insights into the process of metal reduction using rotary hearth furnace.

- A scaled-up version of a single pellet model to a multi-pellet layer version provides an effective model for estimating various parameters at a significant reduction of computational cost.
- The degree of reduction is the primary point of concern for pellets and depends largely on the kinetics of the reaction and the type of carbon chosen. This leads to a change in the degree of reduction and this parameter could be exploited for industrial productivity.

- The $\mathrm{C} / \mathrm{O}$ ratio in a pellet process for a certain range of 1 to 1.5 has negligible impact on the pellet reduction.

- The DOR-value remains below 100 pet for temperatures lower than $1373 \mathrm{~K}\left(1100{ }^{\circ} \mathrm{C}\right)$, even for reduction times of 20 minutes or longer.

- Heat is absorbed primarily at the beginning of the reaction and the rate of heat absorption decreases with time. This is attributed to the decrease in the rate of the endothermic Boudouard reduction. 


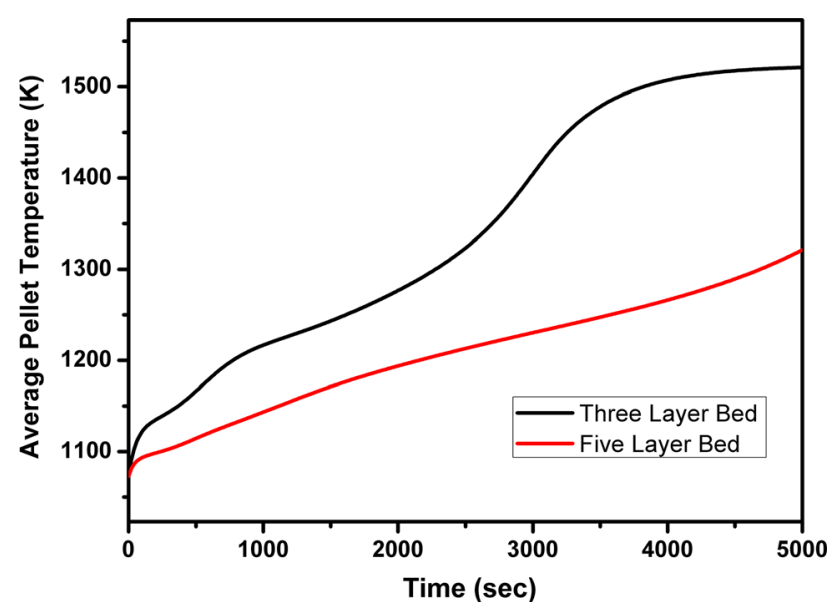

Fig. 11-Variation of heat flux with time for a five-pellet bed layer system $\mathrm{C} / \mathrm{O}$ ratio being 1 in the pellets at furnace temperature 1523 $\mathrm{K}\left(1250{ }^{\circ} \mathrm{C}\right)$.

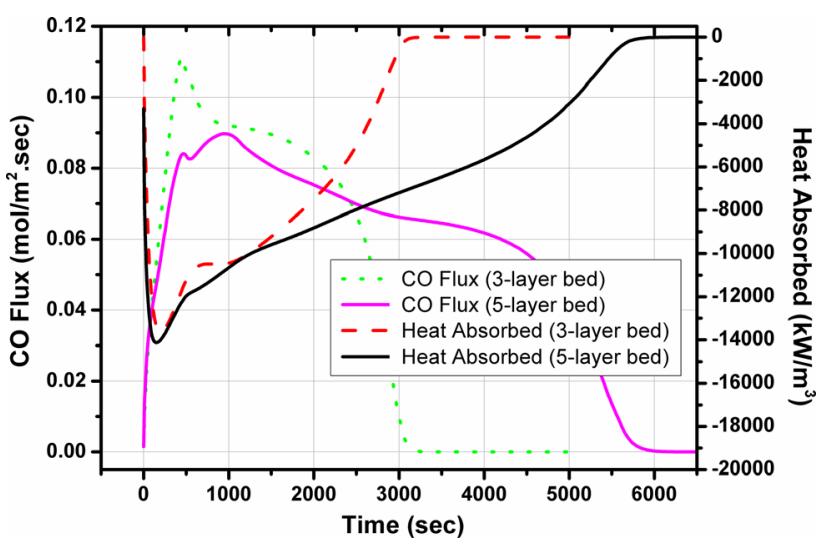

Fig. 12-Variation of absorbed heat and evolved $\mathrm{CO}$ flux with time for a five-pellet bed layer system with $\mathrm{C} / \mathrm{O}$ ratio being 1 ratio in the pellets at furnace temperature $1523 \mathrm{~K}\left(1250{ }^{\circ} \mathrm{C}\right)$.

- An increased number of pellet layers in the bed leads to a lower degree of reduction towards the bottom of the RHF due to the reduced local heating rates in these areas. Thus, an increase of the number of pellet layers may not be a viable way to increase productivity.

The pressure gradient across the pellet bed is low and hence a low velocity of escaping gases was observed across the pellet bed.

\section{OPEN ACCESS}

This article is licensed under a Creative Commons Attribution 4.0 International License, which permits use, sharing, adaptation, distribution and reproduction in any medium or format, as long as you give appropriate credit to the original author(s) and the source, provide a link to the Creative Commons licence, and indicate if changes were made. The images or other third party material in this article are included in the article's Creative Commons licence, unless indicated otherwise in a credit line to the material. If material is not included in the article's Creative Commons licence and your intended use is not permitted by statutory regulation or exceeds the permitted use, you will need to obtain permission directly from the copyright holder. To view a copy of this licence, visit http://creativec ommons.org/licenses/by/4.0/.

\section{REFERENCES}

1. G.P. Singh, Sundeep, R.P. Choudhary, H. Vardhan, M. Aruna, and A.B. Akolkar: Procedia Earth Planet. Sci., 2015, vol. 11, pp. 582-97.

2. J.M. Burgess: ISIJ Int., 1991, vol. 31, pp. 408-17.

3. A. Hasanbegi, M. Arens, and L. Price: Renew. Sustain. Energy Rev., 2014, vol. 33, pp. 645-58.

4. N.S. Srinivasan and A. Lahiri: Metall. Trans. B., 1977, vol. 8, pp. 175-78.

5. T. Coetsee, P.C. Pistorius, and E.E. De Villiers: Miner. Eng., 2002, vol. 15, pp. 919-29.

6. K. Sun and W.K. Lu: Metall. Mater. Trans. B Process Metall. Mater. Process. Sci., 2009, vol. 40, pp. 91-103.

7. M.K. Sharma, V. Solanki, G.G. Roy, and P.K. Sen: Ironmak. Steelmak., 2013, vol. 40, pp. 590-97.

8. R.J. De Carvalho, P.G. Quariguasi Netto, and J.C. D'abreu: Can. Metall. Q., 2014, vol. 33, pp. 217-25.

9. I. Sohn and R.J. Fruehan: Metall. Mater. Trans. B Process Metall. Mater. Process. Sci., 2006, vol. 37, pp. 223-29.

10. T. Huang, S.-H. Liu, and G.-H. Shiau: China Steel Techn. Rep, 2014, vol. 27, pp. 11-19.

11. E. Donskoi, D. McElwain, and L.J. Wibberley: Metall. Mater. Trans. B Process Metall. Mater. Process. Sci., 2003, vol. 34B, pp. 255-66.

12. E. Donskoi and D.L.S. McElwain: Metall. Mater. Trans. B Process Metall. Mater. Process. Sci., 2003, vol. 34B, pp. 93102.

13. M.S. Valipour and Y. Saboohi: Model. Simul. Mater. Sci. Eng., 2007, vol. 15 , pp. 487-507.

14. J.S. Foster, J. Velasco, and C.E. Seaton: Trans. Iron Steel Inst. Japan, 1983, vol. 23, pp. 490-96.

15. T. Akiyama, H. Ohta, R. Takahashi, Y. Waseda, and J. Yagi: ISIJ Int., 1992, vol. 32, pp. 829-37.

16. W. Sun, C.A.V. Costa, and A.E. Rodrigues: Chem. Eng. J., 1995, vol. 0467 , pp. $285-94$

17. D.R. Poirier and G.H. (Gordon H. Geiger: Transport Phenomena in Materials Processing, 1937.

18. O.M. Fortini and R.J. Fruehan: Metall. Mater. Trans. B Process Metall. Mater. Process. Sci., 2005, vol. 36, pp. 865-72.

19. S. Halder and R.J. Fruehan: Metall. Mater. Trans. B Process Metall. Mater. Process. Sci., 2008, vol. 39, pp. 796-808.

Publisher's Note Springer Nature remains neutral with regard to jurisdictional claims in published maps and institutional affiliations. 